Revista Bioética

\title{
PESQUISA
}

\section{Termo de consentimento informado: impacto na decisão judicial}

Merlei Cristina Manzini ${ }^{1}$, Carlos D'Apparecida Santos Machado Filho ${ }^{1}$, Paulo Ricardo Criado ${ }^{1}$

1. Departamento de Dermatologia, Faculdade de Medicina do ABC, Santo André/SP, Brasil.

\section{Resumo}

O termo de consentimento informado é fundamental na relação jurídica entre médico e paciente. Visando avaliar seu impacto na sentença judicial, realizou-se estudo retrospectivo de 70 processos de responsabilidade civil envolvendo procedimentos médicos estéticos cirúrgicos e não cirúrgicos com termo de consentimento assinado pelos pacientes. Os casos analisados, julgados entre 2014 e 2016, foram selecionados nos sites dos tribunais brasileiros e classificados em dois grupos: médicos absolvidos (51\%) e condenados (49\%). No primeiro grupo, 39\% das absolvições se embasaram na apresentação adequada do termo de consentimento informado, enquanto, no segundo, $50 \%$ dos médicos foram condenados por não o ter incluído. Portanto, o termo de consentimento informado se destaca nos julgamentos de erro médico. O dever de informar é um dos pilares da responsabilidade civil desse profissional e, quando negligenciado, constitui fator substancial para condenação.

Palavras-chave: Consentimento livre e esclarecido. Responsabilidade pela informação. Estética. Responsabilidade civil. Erros médicos.

\section{Resumen}

Formulario de consentimiento informado: impacto en la decisión judicial

El formulario de consentimiento informado es fundamental en la relación jurídica entre médico y paciente. Para evaluar su impacto en sentencias judiciales, se realizó un estudio retrospectivo con 70 procesos de responsabilidad civil relacionados con procedimientos médicos estéticos quirúrgicos y no quirúrgicos con el formulario de consentimiento firmado por los pacientes. Los casos analizados, juzgados entre 2014 y 2016, fueron seleccionados en los sitios web de los tribunales brasileños y clasificados en dos grupos: médicos absueltos (51\%) y condenados (49\%). En el primer grupo, el 39\% de las absoluciones se basaron en la presentación adecuada del formulario de consentimiento; en el segundo, en el $50 \%$ de los casos se condenaron a los médicos por no incluir este documento. Por tanto, el formulario de consentimiento informado se destaca en los juicios por error médico. El deber de informar es uno de los pilares de la responsabilidad civil del médico, y su incumplimiento constituye un factor sustancial de condena.

Palabras clave: Consentimiento informado. Deber de advertencia. Estética. Responsabilidad civil. Errores médicos.

\begin{abstract}
Informed consent: impact on court decisions

The informed consent form is essential in the physician-patient relationship. To evaluate its impact on court decisions, we conducted a retrospective study of 70 civil suits involving surgical and non-surgical aesthetic medical procedures with an informed consent form signed by patients. The cases, judged between 2014 and 2016, were selected from Brazilian courts websites and classified into two groups: acquitted (51\%) and convicted (49\%) doctors. In the first group, 39\% of acquittals were based on the proper presentation of the informed consent form, whereas in the second $50 \%$ of the professionals were convicted for not including the document. The informed consent thus stands out when judging medical errors, and the duty to warn is one of the pillars of the professional liability and, when neglected, becomes a substantial factor for their conviction. Keywords: Informed consent. Duty to warn. Esthetics. Damage liability. Medical errors.
\end{abstract}

Declaram não haver conflito de interesse. 
O Código de Defesa do Consumidor $(C D C)^{1}$ inovou a relação entre médico e paciente ao caracterizar o primeiro como prestador de serviço e o segundo como cliente. Essa novidade enfatizou a responsabilidade civil do profissional, na qual prepondera o dever de informar, como expressam os seguintes artigos desse Código:

\section{Art. 6ㅇ São direitos básicos do consumidor:}

(...)

III - a informação adequada e clara sobre os diferentes produtos e serviços, com especificação correta de quantidade, características, composição, qualidade, tributos incidentes e preço, bem como sobre os riscos que apresentem;

\section{(...)}

Art. 8o Os produtos e serviços colocados no mercado de consumo não acarretarão riscos à saúde ou segurança dos consumidores, exceto os considerados normais e previsíveis em decorrência de sua natureza e fruição, obrigando-se os fornecedores, em qualquer hipótese, a dar as informações necessárias e adequadas a seu respeito.

\section{(...)}

Art. 9o o fornecedor de produtos e serviços potencialmente nocivos ou perigosos à saúde ou segurança deverá informar, de maneira ostensiva $e$ adequada, a respeito da sua nocividade ou periculosidade, sem prejuízo da adoção de outras medidas cabíveis em cada caso concreto ${ }^{1}$.

Ao paciente, respaldado pelo princípio constitucional da dignidade da pessoa humana, é facultado decidir como deseja viver sua vida, o que inclui quaisquer tratamentos médicos. Desse modo, possui também autonomia na elaboração do termo de consentimento informado ( $\mathrm{TCl}$ ) quando isso não prejudicar a boa técnica nem ferir a ética médica com consequente prejuízo ao tratamento proposto. O paciente pode igualmente revogar o documento a qualquer tempo antes do procedimento, sem anuência do profissional assistente, denotando a integridade ética, honestidade e boa-fé na relação. Tais princípios estão expressos na Constituição Federal, cujo artigo 10, inciso III, estabelece a dignidade da pessoa humana como fundamento da República, e cujo artigo 5, inciso II, determina que ninguém será obrigado a fazer ou deixar de fazer alguma coisa senão em virtude de $l e i^{2}$.

O novo Código de Ética Médica $(C E M)^{3}$ se coaduna com a interpretação da Carta Magna, respeitando a dignidade da pessoa humana em relação à autonomia do paciente. Apesar de alterar a redação, o novo código manteve a proposta desse dispositivo ${ }^{2}$ e do $\mathrm{CDC}^{1}$ no sentido de priorizar a importância da informação. Confrontando a atual versão do CEM com outra anterior, nota-se mudança. O texto de 1988, em seu artigo 46, proíbe o profissional de efetuar qualquer procedimento médico sem o esclarecimento e o consentimento ${ }^{4}$ do paciente, enquanto o artigo 22 do CEM de 2018 veda ao médico deixar de obter consentimento do paciente ou de seu representante legal após esclarecê-lo sobre o procedimento a ser realizado ${ }^{3}$.

Essa mudança estabelece a importância do dever de informar na esfera jurídica, e tribunais de todo o Brasil tratam a questão com cada vez mais rigor. Porém, não basta declarar verbalmente que o paciente foi informado, é preciso prová-lo por escrito, em documento assinado: o TCl. Conforme o inciso XXI do Capítulo I do CEM em vigor, no processo de tomada de decisões profissionais, de acordo com seus ditames de consciência e as previsões legais, $o$ médico aceitará as escolhas de seus pacientes relativas aos procedimentos diagnósticos e terapêuticos por eles expressos, desde que adequadas ao caso $e$ cientificamente reconhecidas ${ }^{3}$.

Apesar de dois atores participarem da elaboração do $\mathrm{TCl}$, não se trata de contrato de prestação de serviços, mas de ato jurídico unilateral, que não gera direito ao médico. Serve como meio de informar e validar o próprio Código Civil, que dispõe em seu artigo 13 que, salvo por exigência médica, é defeso o ato de disposição do próprio corpo, quando importar diminuição permanente da integridade física, ou contrariar os bons costumes, complementado pelo artigo 15, que estabelece que ninguém pode ser constrangido a submeter-se, com risco de vida, a tratamento médico ou a intervenção cirúrgica ${ }^{5}$. No âmbito do direito civil, o dever de informar está na obrigação do profissional de saúde de explicar clara e especificamente o serviço que será prestado ao paciente, com base no princípio da boa-fé objetiva nas relações de confiança ${ }^{6}$.

O termo de consentimento livre e esclarecido é semelhante ao $\mathrm{TCl}$ e também segue os princípios constitucionais de autonomia e dignidade pessoal, mas diverge no objetivo. É exigido em toda pesquisa que envolva seres humanos, sendo assinado pelo próprio indivíduo ou grupo participante ou por seu representante legal para autorizar sua inclusão no estudo, conforme as diretrizes e normas regulamentadoras do Conselho Nacional de Saúde ${ }^{7}$.

Dado o significativo aumento do número de processos contra médicos após o advento do CDC, torna-se imperioso investigar a real efetividade jurídica do $\mathrm{TCl}$ na defesa desses profissionais. 


\section{Método}

Foi realizado estudo retrospectivo ${ }^{8}$ dos acórdãos de cortes de todo o Brasil proferidos entre 2014 e 2016, obtidos nos sites dos tribunais ${ }^{9}$. $\mathrm{Na}$ busca utilizaram-se as palavras-chave "cirurgia estética-termo de consentimento informado", "procedimento estético-termo de consentimento informado" e "termo de consentimento informado em estética". Selecionaram-se 70 julgados em que o $\mathrm{TCl}$ fora aplicado adequadamente, com assinatura do paciente autorizando procedimentos estéticos cirúrgicos e não cirúrgicos. O Judiciário considera somente $\mathrm{TCl}$ escritos, por isso os designados como verbais ou não encontrados foram tidos como ausentes.

Com as informações colhidas, provenientes da sentença judicial, foi possível analisar os processos e as razões que ensejaram a conclusão de cada caso. No escopo desta pesquisa, denomina-se como causa de absolvição ou condenação o TCl, com suas variáveis "fornecido" e "não fornecido", além de nexo causal ausente/presente; culpa ausente/presente; TCI fornecido somado a outro motivo; obrigação de resultados. Estas últimas variáveis são agrupadas em "outros".

\section{Resultados e discussão}

A amostra de 70 casos foi dividida em dois gru$\operatorname{pos}^{8}:$ 1) médicos absolvidos (36); e 2) médicos condenados (34). No geral, a taxa de condenação por erro médico foi de $49 \%$, contra $51 \%$ de absolvição. No grupo 1 a absolvição ocorreu em 39\% dos casos devido ao $\mathrm{TCl}$ aplicado adequadamente, e em $61 \%$ por outras causas. No grupo 2, a falta do TCl representou $50 \%$ dos motivos de condenação elencados.

Historicamente, a primeira decisão jurisprudencial relatada a respeito do TCl foi o caso Schloendorff v. Society of New York Hospitals, ocorrido nos Estados Unidos em 1914. Segundo Faden e Beauchamp, na sentença o juiz Benjamin Cardozo afirma que todo ser humano em idade adulta e com capacidade mental normal tem o direito de determinar o que será feito no seu próprio corpo ${ }^{10}$. Essa afirmação é considerada clássica pelos especialistas.

Os estudiosos brasileiros não chegaram a um consenso sobre a tradução da expressão inglesa "informed consent", variando na língua portuguesa entre os termos "consentimento pós-informação", "consentimento consciente" e, o mais comum, "consentimento informado". A responsabilidade civil do médico em informar o paciente antes dos procedimentos tornou-se relevante no país em 1990, com o advento do CDC, que, como já apontado, define esse profissional como prestador de serviços. Porém, diferentemente de outros profissionais, sua responsabilidade será apurada mediante a verificação de culpa ${ }^{1}$.

O conceito de "consumo" relacionado aos serviços de saúde ampliou o número de processos contra esses profissionais, mas em muitos casos a interpretação de "erro médico" é incorreta, bastando a ocorrência de dano para configurar a responsabilidade médica sem que a culpa seja estabelecida. No entanto, o descumprimento do dever de informar é expressivo e configura erro profissional, concorrendo para sua condenação.

Ao médico compete a responsabilidade civil subjetiva, aquela em que a vítima deverá provar que o dano decorreu por culpa stricto sensu (imprudência, negligência e imperícia) e lato sensu (dolo) do agente. A mais ligeira culpa obriga o agente a indenizar a vítima, mesmo sem dolo ${ }^{11}$. Em certos casos não se exige prova da culpa, bastando sua presunção, em que se verifica inversão do ônus da prova. Cabe, então, ao demandado afastar a presunção de culpa, provando não ter tido responsabilidade pelo dano.

Há certos requisitos para apurar a responsabilidade do médico, conforme o artigo 186 do Código Civil: 1) conduta culposa do agente, patente na expressão aquele que, por ação ou omissão voluntária, negligência ou imprudência; 2) nexo causal, expresso no verbo causar; 3) dano, revelado nas expressões violar direito e causar dano a outrem ${ }^{5}$. Portanto, não basta constatar o dano para confirmar a responsabilidade civil do médico e sua consequente condenação; é necessário averiguar os pressupostos da norma positivada.

O TCl deve respeitar certas regras para ser validado juridicamente. Como em todo contrato, a capacidade civil é fundamental, e portanto o texto deve ser claro para o bom entendimento do cidadão médio, com letras em tamanho legível e conteúdo individualizado. Também precisa ser assinado voluntariamente, sem qualquer coerção, pelo próprio paciente ou por seu representante legal. 0 paciente deve participar ativamente na elaboração desse documento - sempre tendo sua autonomia respeitada -, desde que isso não interfira na boa técnica profissional. Caso contrário, o médico arcará sozinho com todo o ônus da intervenção ${ }^{12}$.

Como já apontado, o $\mathrm{TCl}$ é ato jurídico unilateral, que não gera direito ao médico; ou seja, seus efeitos são limitados à manifestação de vontade do 
paciente ${ }^{13}$. Apesar de essencialmente produzido para garantir os direitos do consumidor, o $\mathrm{TCl}$ vem sendo visto pelo Judiciário como importante ferramenta de defesa médica, quando adequadamente aplicado, configurando relação de equidade, equilibrada, segura e confiável, traduzindo o cumprimento do dever profissional de informar.

\section{Procedimentos estéticos}

Os procedimentos estéticos são peculiares quando comparados aos de cunho terapêutico. Nesse caso o paciente é totalmente hígido, mas procura o médico a fim de melhorar sua aparência e autoestima, esperando que seu investimento Ihe traga conforto psicológico ${ }^{14}$. O médico necessita ter sensibilidade apurada para atender esse tipo de paciente, e após a triagem é ainda incumbido de informar-lhe todos os pormenores do procedimento. Desta forma, o dever de informar torna-se muito mais criterioso que para as demais intervenções médicas.

Atualmente se verifica grande insatisfação com resultados de procedimentos estéticos. Isso denota a percepção subjetiva do paciente em relação às suas expectativas e demonstra equívoco na interpretação do $C D C$, pois o médico não pode responder pelo descontentamento pessoal de outrem, tampouco pelos traumas psicológicos de uma vida.

Diante do enaltecimento do TCl pelo Judiciário, sobretudo nos procedimentos estéticos, observou-se a necessidade de avaliar a real efetividade jurídica dessa ferramenta na defesa do profissional. 0 impacto desse documento na decisão judicial pode ser avaliado analisando-se os julgados de procedimentos estéticos cirúrgicos e não cirúrgicos. Nos casos avaliados nesta pesquisa, verificou-se a incidência quase equiparada de absolvição (51\%) e condenação (49\%) do médico. Distinguiu-se o erro técnico (culpa) do dever de informar para melhor avaliar o escopo. A absolvição do profissional pela adequada aplicação do TCl foi expressiva (39\%), contra outras causas que impeliram o Judiciário a decidir em prol do médico. Entretanto, $50 \%$ das condenações foram motivadas pela ausência do $\mathrm{TCl}$, denotando enorme importância do documento como forma de defesa médica.

Convém salientar que muitos problemas advêm de situações independentes da ação médica, inerentes ao procedimento e a qualquer indivíduo, mas que frequentemente são considerados pelos pacientes como erro médico. Da mesma forma, a falta do $\mathrm{TCl}$ é vista pelo Judiciário como negligência profissional, mesmo que não haja erro de técnica.

Os resultados obtidos neste estudo permitem afirmar que muitos julgadores consideram a ausência do $\mathrm{TCl}$ como motivo suficiente para condenar o profissional, entendendo que isso denota falta de ética e boa-fé do médico em cumprir seu dever de informar o paciente e respeitar os princípios de autonomia e dignidade da pessoa humana. $O$ paciente tem o direito de conhecer todos os pormenores do procedimento para que, assim, possa escolher realizá-lo ou não.

\section{Considerações finais}

Nesta pesquisa, apesar do número quase equiparado de absolvições e condenações, a devida aplicação do $\mathrm{TCl}$ teve enorme impacto na exculpação dos médicos. A maior influência na condenação foi a falta desse documento, confrontando diretamente os princípios legais de autonomia e dignidade da pessoa humana. Podemos concluir com isso que o TCl concorre com os pilares da responsabilidade civil já bem estabelecidos no universo jurídico. Esse documento ocupa posição primordial na rotina médica, sobretudo em procedimentos estéticos, quando o paciente está totalmente saudável e procura somente melhorar sua aparência física. O TCl constitui prova incontestável a ser usada pelo médico em sua defesa.

\section{Referências}

1. Brasil. Lei no 8.078 , de 11 de setembro de 1990. Dispõe sobre a proteção do consumidor e dá outras providências. Diário Oficial da União [Internet]. Brasília, 12 set 1990 [acesso 21 jan 2020]. Disponível: https://bit.ly/3gk7BFO

2. Brasil. Constituição da República Federativa do Brasil 1988. Brasília: Senado Federal; 1988.

3. Conselho Federal de Medicina. Resolução CFM no 2.217, de 27 de setembro de 2018. Aprova o Código de Ética Médica. Diário Oficial da União [Internet]. Brasília, 1o nov 2018 [acesso 21 jan 2020]. Disponível: https://bit.ly/3jXfAKQ

4. Conselho Federal de Medicina. Resolução CFM no 1.246, de 8 de janeiro de 1988. Código de Ética Médica. Diário Oficial da União [Internet]. Brasília, 26 jan 1988 [acesso 6 ago 2020]. Disponível: https://bit.ly/3almfug 
5. Brasil. Lei no 10.406, de 10 de janeiro de 2002. Institui o Código Civil. Diário Oficial da União [Internet]. Brasília, 11 jan 2002 [acesso 21 jan 2020]. Disponível: https://bit.ly/33dReXi

6. Marques CL. A responsabilidade dos médicos e do hospital por falha no dever de informar ao consumidor. Rev Trib. 2004;93(827):11-48.

7. Conselho Nacional de Saúde. Resolução CNS 196/1996. Aprova diretrizes e normas regulamentadoras de pesquisas envolvendo seres humanos. Bioética [Internet]. Porto Alegre: UFRGS; [s.d.] [acesso 21 jan 2020]. Disponível: https://bit.ly/3fcX8uc

8. Manzini MC. Valor jurídico do termo de consentimento informado em procedimentos estéticos [dissertação]. Santo André: Faculdade de Medicina do ABC; 2018.

9. Links: Tribunais. ConJur [Internet]. [s.d.] [acesso 21 jan 2020]. Disponível: https://bit.ly/2DiWCOc

10. Faden RR, Beauchamp TL. A history and theory of informed consent. Nova York: Oxford University Press; 1986. p. 392

11. Melo ND. Responsabilidade civil por erro médico: doutrina e jurisprudência. 2ª ed. São Paulo: Atlas; 2013.

12. Stancioli BS. Relação jurídica médico-paciente. Belo Horizonte: Del Rey; 2004.

13. Roberto LMP. Responsabilidade civil do profissional da saúde e consentimento informado. Curitiba: Juruá; 2006.

14. Magalhães TAL. O dano estético: responsabilidade civil. 2ª ed. São Paulo: Editora Revista dos Tribunais; 1999.

\section{Participação dos autores}

Merlei Cristina Manzini desenvolveu a pesquisa bibliográfica e redigiu o manuscrito. Carlos D’Apparecida Santos Machado Filho e Paulo Ricardo Criado orientaram o estudo e revisaram o artigo.

\section{Correspondência}

Merlei Cristina Manzini - Av. Dom Pedro II, 125, sala 133, Jardim CEP 09080-110. Santo André/SP, Brasil.

Merlei Cristina Manzini-Mestre-mcmanz@uol.com.br

(iD) 0000-0002-1816-0294

Carlos D'Apparecida Santos Machado Filho - Livre-docente - carmachado@terra.com.br (iD) 0000-0003-4362-1563

Paulo Ricardo Criado - Livre-docente - prcriado@uol.com.br

(iD) 0000-0001-9785-6099

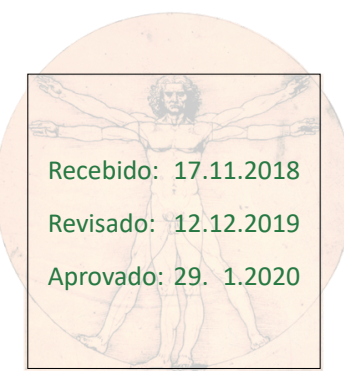

